\title{
Ecos De STRINDBERG: DOR E MEDO NA CLÍNICA PSICANALÍTICA EM EXTENSÃO
}

\author{
Gisálio Cerqueira Filho*
}

\section{RESUMO}

O presente ensaio aborda o teatro intimista do dramaturgo sueco Auguste Strindberg (1849-1912) nas suas implicações tanto com a Ciência Política quanto com a Psicanálise. São ressaltadas algumas relações entre ideologia, poder, autoridade e responsabilidade parental do Estado, tendo como cenário o pensamento de Strindberg e o eco produzido na modernidade; com um breve destaque para a influência produzida no cineasta Ingmar Bergman. O foco é a psicanálise em extensão.

Palavras-chave: Strindberg, sofrimento psíquico, clínica em extensão

\section{ABSTRACT}

STRINDBERG'S ECHOES: PAIN, FEAR AND PSYCHOANALYSIS ON EXTENSION

This essay focuses the intimist dramaturgy of the Sweden writer Auguste Strindberg (18491912), and its relations with Social Sciences, specially Political Science and Psychoanalysis. Relations between ideology, power, authority and the States's parental responsibility are in the scene. Strindberg's thought and its modernity are considered through the influence on Ingmar Bergman's life in the cinema. The focus is psychoanalysis on extension.

Keywords: Strindberg, suffering, psychoanalysis on extension

* Doutor em Ciência Política, Professor Titular de Sociologia, Pesquisador no Laboratório de Psicopatologia Fundamental, Psicanálise e Psicossomática (LP3F) da UFF, Membro da Associação Universitária de Pesquisa em Psicopatologia Fundamental (AUPPF). 
Para Joana, minha neta recém-nascida.

A implicação da psicanálise com o teatro (Cerqueira Filho, 2001) não é de hoje e por isso a escritura da peça "X, Y e S: a abertura do Teatro Íntimo de Strindberg: uma experiência de psicanálise implicada com o teatro" ${ }^{1}$, autoria, dramaturgia e direção geral de Antonio Quinet, é muito bem-vinda, além de fecunda. Diz o programa: "telescopando datas, textos, biografias e personagens, o psicanalista Antonio Quinet propóe com este espetáculo uma experiência de psicanálise implicada no teatro".

O fato é que o discurso e a prática de August Strindberg (1894-1912) ainda provocam um som estridente, agudo e penetrante, um ruído estrepitoso, que ressoa quase um século após sua morte. E esse novo empreendimento teatral o atesta. Ainda que, segundo a crítica de teatro Bárbara Heliodora (2005), A. Quinet tenha se transformado em dramaturgo e diretor de teatro num processo de transbordamento do papel de consultor que lhe fora primeiramente reservado pelo grupo teatral ${ }^{2}$. Daí a observação "psicanálise demais, teatro de menos", no entender da jornalista. Pode ser, vá lá...

Mas a verdade é que os textos de Strindberg "A mais forte" (1890), "O Pai" (1887), "Srta. Júlia" (1888), entre outros, se prestam admiravelmente para uma crítica da ideologia a partir do laço entre a ciência política e a psicanálise. Se é verdade que há muitas cenas que trafegam da vida real do autor sueco para o teatro que escreve é porque deliberadamente Strindberg sempre aproximou o seu trabalho como artista (escritor, teatrólogo, pintor, fotógrafo, etc) dos dramas existenciais vividos por ele mesmo e que não foram poucos. O próprio Freud admitia, em 1895, que tinha a impressão curiosa de que as histórias clínicas que escrevia deviam ser lidas como novelas (Ricci, 2005: 126)...

A peça em si remete à abertura do Teatro Íntimo ${ }^{4}$, que funcionou de $1910 \mathrm{a}$ 1917, com a estréia da peça "A mais forte" estrelada por Siri Von Essen, sua esposa e com quem teve três filhos, no papel de senhora "X". Já a inicial "Y" remete à amiga do casal Marie Caroline David. O título "X, Y e S" evoca, ainda, não apenas os cromossomos masculino e feminino, mas a tríade Senhora "X", Senhorita "Y", bem mais jovem e encantadora, e o próprio Strindberg nomeado pela letra "S". Numa aproximação das letras "Y" (maiúscula) e "S" (também maiúscula) mediadas pelo conectivo "e" temos o título bem sugestivo que salta à vista do espectador "X, YeS" onde "Yes" é expressão que se refere a um significante de obediência e submissão tomistas (relativo ao pensamento de Santo Tomás de Aquino), tão fortes no teatro de Strindberg. Não é por outra razão que o texto da peça é pontuado pela expressão constante "Yes, darling", sugerindo a prontidão, o estar à disposição do outro; tanto quanto "cala a boca e atua", indicativo do papel que 
caberia às mulheres: participação, atuação (até certo ponto), mas de boca calada, isto é, sem uma genuína participação política. No texto, as alusões de que Strindberg não apoiava o voto das mulheres não só o coloca no campo do antifeminismo político-eleitoral, mas também naquele da prática política (feminista?) que encara a diferença de gênero e sexo como "luta pra valer". Não é à-toa que utiliza as expressōes "luta de sexos" e "guerra de cérebros". O título "A mais forte" é já uma insinuação, entretanto misógina, de que a mulher é mais forte que o homem porque detém o controle basicamente da reprodução da vida, cabendo ao homem um papel acessório e subordinado. Há aqui um toque de ressentimento. O "Yes, darling" tem ainda um equivalente nas cartas que o escritor Franz Kafka escreveu à sua noiva Félice e que foram interpretadas por Elias Canetti ${ }^{5}$ como um "outro processo", que corre à revelia e ecoa na obra "O processo" ", tanto no culto ao sono quanto na repetição constante do refrão "Dorme! Dorme!” dirigido à mulher, quando Kafka está preocupado com o estado de exaltação ou inquietação dela. O sono é visto como uma panacéia ou remédio para tudo, nos termos de uma obediência, submissão e concordância com relação à opinião do homem, uma espécie de passividade levada ao extremo - maior que isto só a morte - mas que é percebida por Canetti também como "uma exortação algo semelhante a um exorcismo ou a uma benção" (Canetti, 1998: 33)... O que não exclui que a insônia seja interpretada como perigosa.

Em termos de psicopatologia fundamental (Berlinck, 2000), há ainda toda uma problemática sugerida por Canetti, à qual não está alheia a obra de Strindberg. Estou referindo-me aqui ao quanto os estados psíquicos estão imbricados com estados físicos e orgânicos. Há sintomas variados referidos a dores em distintos órgãos e difusamente espalhados pelo corpo que falam de uma vulnerabilidade física e recordam a existência do mesmo. Negligenciá-las seria imprudência e por isso são precursoras do "inimigo". Podemos então falar que "a hipocondria é o troco miúdo da angústia e a angústia, para distrair-se, procura e encontra nomes" (Canetti, 1998: 33). Tal é o terreno em que se manifesta a insuficiência imunológica psíquica, nos termos propostos por Manoel Berlinck (2000).

Já a presença da jovem Marie Caroline David, que Strindberg e Siri conheceram em Grez-sur-Loing, na França, permite o contraponto para os diálogos entre a senhora "X" e a senhorita "Y"; melhor seria falar em monólogo em voz alta da senhora "X", pois a senhorita "Y" quase nunca fala... Também o recurso de colocar em cena duas atrizes fazendo o mesmo papel sugere a repetição do sintoma em meio a uma hemorragia verbal. Como a peça, mesmo predominando Strindberg, é uma colagem de variados textos, devemos ressaltar em particular algumas pontuaçôes textuais baseadas em Shakespeare, James Joyce, Freud e Lacan, além da peça The night of the Tribades, de Olov Enquist. 
A ambientação cenográfica é de Anna Bella Geiger, com destaque para o grande espelho inclinado que reflete múltiplos arquivos de aço dispostos no chão, sugerindo os arquivos da memória sonora ruidosamente convocados, também na projeção de um enquadramento visual no qual contracenam "X", "Y" e "S". Na tela, de tamanho médio e ao fundo dos personagens, "Geiger d'après sua instalação Indiferenciados", ejeta para o exterior os arquivos do sujeito: sua memória, seus sonhos, seus delírios, seus desejos. A instalação da artista plástica Anna Bella Geiger, além de esplêndida, encaixa-se com perfeição na intenção de realizar um jogo psicanalítico: o telão mostra cenas que, misturando-se às sombras dos atores, criam uma fusão onírica, irreal, mas que compõe os embates a sua frente, como uma só cena; o gabinete, jogado ao chão, no centro, aberto, com suas gavetas espalhadas e vazias, ou seja, o íntimo, o inconsciente, os desejos e fantasias mais secretos, mais recalcados, libertos, aparentes.

Isto nos faz lembrar do escritor Gabriel Garcia Márquez na sua obra Vivir para contarla, quando diz na abertura da mesma: "la vida nos es la que uno vivió sino la que uno recuerda y como recuerda para contarla" (Márquez, 2002: 6). O acento da citação é bem "lacaniano" e tal é o estridente em Strindberg: recordar-se de um certo jeito e falar sem parar, desde este ângulo, de modo insistente, repetido, incessante.

A música, ao piano, de Sigga Malaguti busca marcar o compasso rítmico dos processos psíquicos de Strindberg, sugerido nas notas de Bach, Beethoven, Bártok e Koellreutter; a vibração do silêncio da "pulsão de morte" (Tânatos) em meio à pulsão de vida (Eros) numa alusão ao alarido dos combates de cérebros e sexos.

A luz de Aurélio de Simoni sugere o intimismo como bem queria Strindberg para o seu teatro; é escura, mas não em demasia. As sombras projetadas produzem efeitos múltiplos de ilusão. O som do piano, o burburinho das falas, o barulho demasiado estridente da projeção, o vai-e-vem do personagem "S" (o próprio autor Strindberg) conferem ao espetáculo um colorido que a luz soturna não sobrepõe.

No último capítulo de "Brás Cubas" (cap. CLX), intitulado "Das negativas" (Machado de Assis, 1880/1979), Machado de Assis ressalta um elenco delas, mas diz explicitamente com relação ao personagem central que este não conhecera o casamento e, feitas as contas, considerava-se praticamente quite com a vida. $\mathrm{O}$ autor diz que, na verdade, há um pequeno saldo inscrito no que chama de derradeira negativa deste capítulo das negativas: "Brás Cubas não tivera filhos, não transmitira a nenhuma criatura o legado da nossa miséria" (Machado de Assis, 1880/1979: 639).

A conclusão imponente é uma espécie de salvaguarda para a paternidade, uma espécie de racionalização capaz de evitar o lugar da figura paterna para si 
próprio. O tema é recorrente na obra da Franz Kafka: "nunca terei um filho", diz ele a Félice em carta de 8 de novembro de 1912. Mais tarde, transcreve uma citação de Napoleão Bonaparte ainda para Félice: "é terrível morrer sem filhos". E logo “... nunca me será permitido expor-me ao risco de ser pai” (Canetti, 1998: $40-41) \ldots$

Um certo eco de Strindberg pode ser observado na peça que estreou em Berlim no segundo semestre de 2004 no teatro Neuköllner: trata-se da ópera "Licht" (Luz), do compositor Wolfgang Böhmer, com libreto de Dea Loher. A ópera em cartaz conta a estória de uma mulher confinada ao papel exclusivo de esposa que, todavia, sonha com um mundo melhor; mas acaba completamente isolada, vivenciando o individualismo fóbico na sua mais completa radicalidade. A mulher em questão é nada mais nada menos que Hanellore Kohl, que foi casada com o chanceler federal da Alemanha Ocidental Helmuth Kohl. O chanceler governou a Alemanha de 1982 a 1998 (dezesseis anos!) e certamente entrou para a história por ter conseguido a reunificação alemã durante o seu mandato. Cavalgou a "fortuna", mas teve a "virtu" de distinguir para onde sopravam os ventos da política logo após a queda do muro de Berlim. Para tal finalidade, contou com o apoio não apenas dos EUA e do ocidente, mas também de Mikhail Gorbachev, o número um da então União Soviética, já em processo de franco esfacelamento. Adepto de uma política dura e conservadora, Helmuth Kohl havia sido governador do Palatinado, presidente da União Democrática Cristã, antes de chegar à chancelaria da Alemanha Ocidental e realizar o sonho imprevisto de fazer a reunificação já naquele ano de 1989. Pois bem, o enredo da ópera "Luz" refere-se à estória da esposa do chanceler federal, Hanellore Kohl, que, tendo vivido anos e anos à sombra da figura imponente de Helmuth, acaba por desenvolver uma doença alérgica à luz. Primeiramente, no início da década dos noventa, alergia à luz solar, depois à luz do dia, em seguida à luz elétrica e logo a qualquer luz. Passa a viver então na escuridão, reclusa, afastada de tudo e de todos; iluminação mínima propiciada por fracas lâmpadas de néon. Acaba por suicidar-se.

O libreto da ópera canta a estória na voz de quatro mulheres; uma é a própria Hanellore Kohl, interpretada por Veronika Nickl. As outras três são as suas sombras, contraditórias e fugazes, que sopram sonhos, emoções e tragédias reais que compõem a sua vida. No momento síntese em que Veronika / Hanellore diz "tu (Helmuth) és tão grande, onipotente, que eu já deixei de existir", tudo fica dramaticamente clarificado. Hanellore é filha de uma liderança nazista, sofreu terrivelmente no fim da guerra ao fugir do Leste para Oggersheim, no Palatinado, onde conheceu o marido e viveu até o fim de sua vida. Fluente em francês e inglês, era o protótipo de uma mulher alemã que projetava uma imagem de felicidade: 
bem casada, dois filhos (Peter e Walter), vitoriosa, compartilhando alegrias com um bem-sucedido político alemão. Expressava um apurado perfeccionismo, especialmente nas roupas e no penteado, sempre impecáveis, o que acaba por provocar um pouco a ridicularização da sua figura, tanto na mídia quanto na opinião pública.

Na ópera a mulher lamenta: “... nunca mais lago de Wolfgang ... nunca mais os apertos de mãos", referência ao lugar onde, todos os anos, ia passar as férias com o marido, sempre na mesma aldeia, no mesmo hotel, mas também às cerimônias e jantares oficiais aos quais se impunha comparecer. Aqui não eram propriamente as mãos que se lavavam constantemente e de forma obsessiva, mas as mãos que se apertavam e se apertavam até "o esfacelamento das... juntas", como ela exclama. Numa passagem do seu diário, Gombrowicz (Ribeiro, 1994) fala da Alemanha e de Berlim nos anos sessenta referindo-se a Lady Macbeth e à sua compulsão de lavar as mãos para, num deslocamento clássico, falar do livramento de culpas e remorsos vividos ininterruptamente desde a segunda Grande Guerra. Já que não se consegue tirar as manchas de culpa da alma, tenta-se, na alusão à personagem shakespeareana, limpar as mãos... Aqui, Hanellore Kohl não consegue livrar-se do trauma, lavando as mãos; a compulsão, todavia, continua presente e endereça-se ao aperto frenético, constante e repetido das mãos até que... as juntas se quebrem. As mãos, ainda e sempre, como figuras-chave, como uma espécie de leitmotiv para um trabalho artesanal dedicado, perfeccionista, de destruição de valores até então intocáveis pela humanidade. A pergunta que Gombrowicz se faz - e a ele nós nos associamos na indagação - é se, no contexto alemão, a ruptura com o passado, considerada por muitos como absorvida, consumida e irreversível, continua persistindo. A pergunta que ainda hoje não quer calar vale para o mundo globalizado da atualidade.

O filho Peter Kohl, que já havia contado em livro a tragédia da vida da mãe, atribuía aos horrores da Segunda Guerra mundial os sintomas e fobias maternos. Mas a autora da ópera, Dea Loher, um pouco distintamente, acentua a submissão e a eterna obediência irrestritas ao marido como as causas principais do seu drama.

Não há dúvida de que o compositor Wolfgang Bauer conseguiu imprimir a tensão vivida pela personagem à lentidão das árias, configurando o drama que acentuou o individualismo possessivo até transformá-lo em individualismo fóbico e que culminou com o seu suicídio. Que paradoxo este de os eleitores alemães, em 2005, exigirem uma coalizão entre forças políticas contrárias (CDS/CDU e SPD), com Ângela Merkel como chanceler, a chocar-se com este individualismo fóbico remanescente após a queda do muro de Berlim e a unificação da Alemanha.

Toda a força dramática de A. Strindberg surge fulgurante como fogo de artifício no documentário "Ingmar Bergman: intermezzo", dirigido pelo cineasta 
sueco Gunnar Begdahl em 2002, aproveitando um momento de intervalo da sugestiva peça "Ghost", de Henrik Ibsen (1828-1906).

O filme, que tem a duração de 45 minutos, começa de mansinho com Bergman sugerindo trocar de posição com Gunnar e entrevistá-lo. Acabam sentando-se frente a frente; como quem não quer nada, Gunnar, "entrevistado", vai respondendo a perguntas de Bergman, "entrevistador", e estas acabam por insinuar respostas às suas próprias perguntas. Perguntas que, formuladas por Bergman, dirigem-se menos a Gunnar e mais a ele próprio. O diretor pontua o que parece ser uma entrevista de Bergman com Bergman. É bem interessante.

Então Ingmar Bergman está com 83 anos, morando na ilha de Faro, e fala sobre literatura dramática, com destaque para August Strindberg e Henrik Ibsen, fala sobre como chegou ao gosto pelo cinema, sobre sonhos, a morte, sobre os demônios, sobre insônia e velhice. Resgata do fundo do baú bíblico a história de Abraão e Sara. É uma entrevista bem-humorada realizada numa sala despojada, com alguns equipamentos de cinema e nada mais.

Assim de repente, Bergman assume a fala de Gunnar quando ele se refere a uma citação retirada da "Autobiografia”, de Bergman: “... tenho August Strindberg no meu sangue...” (Begdahl, 2002).

E não apenas porque traduziu "Dream Play" (Begdahl, 2002), do dramaturgo sueco, nem tanto pela linha direta existente entre Ibsen e Strindberg, sendo que no primeiro as coisas estão todas ditas de modo mais sedimentado e, então, o segundo autor pode interpretá-las desde diferentes formas e perspectivas. Nesse sentido, as dramaturgias norueguesas e suecas dialogam a partir de uma linguagem muito peculiar dos países nórdicos europeus. Bergman se esmera por traduzi-las, lê-las, conhecê-las em seus detalhes. Bergman revela que seus momentos de paz eram desfrutados, desde menino, no cinema; vendo e revendo filmes no "escurinho do cinema". Faz isso até hoje, a qualquer hora do dia, no cinema privado de que dispõe na sua casa. Em função da idade, sofre de insônia (Pereira, 2003) e, quando dorme, sonha muito. Não é demais recordar também a célebre citação de Shakespeare "... the very substance of the ambitious is merely the shadow of a dream” (Shakespeare, 1603/1988, Ato II, cena 2: 529).

A propósito de Strindberg, Bergman diz que teve um sonho com ele que the pareceu interessante: iria encontrá-lo numa rua de Estocolmo e recordava-se que devia chamá-lo pelo primeiro nome, "August" (Augusto, mas também "augusto", puro, perfeito, santo, etc) -, o que ele não apreciava tanto. Assim fazendo e falando, Bergman provoca uma sonora homofonia entre "August", "öwghöst" (fantasma, espectro, fantasia, em sueco) e "Ghost" ("Espectro", peça de Ibsen - 1881 que ele estava ensaiando) ${ }^{7}$. August, öwghöst, ghost se insinuam gostosamente como 
fantasia que interpela Bergman na direção da fecundidade criativa. O sintoma convertido em sinthomen (o significante infiltrado pelo gozo) na intrincada rede forjada pelo Simbólico, pelo Imaginário e pelo Real, na acepção de Jacques Lacan.

Diz não temer mais a morte, agora que ela está praticamente presente na sua vida como realidade viva, mas aceita que a temeu muito mais ao longo da vida. Os demônios, todos os demônios, vão embora desde que comecemos um trabalho novo e criativo; também quando nadamos ou realizamos uma boa caminhada, para aludir aos exercícios físicos. Ingmar Bergman produz fragmentos de um discurso que vai na direção da biologia, se entendermos que aqui este termo se refere menos a uma ciência da evolução da vida (fundada por Charles Darwin) ou mesmo a um relato detalhado de natureza anatomofisiológica do corpo (como muitos a entendem na atualidade), mas especialmente como um discurso da vida diante da morte. Diz sentir-se como Sara, capaz de fecundidade, com sua idade avançada, para surpresa de Abraão...

Megalomania, narcisismo, arrogância, autoritarismo absolutista, masoquismo, fixação materna, obsessão, hostilidade, misoginia, mania de perseguição, o parricídio, tudo isto está presente nas relaçōes familiares, e sempre entrelaçado a um aspecto crucial para a Ciência Política: as relações de poder.

No seu "Dança da morte" (1900), Strindberg acentua a reflexão sobre os sentimentos da raiva, do insucesso, da frustração, inscritos em especial no relacionamento de gênero. Trata-se de uma tragédia sociopsicológica na qual estão envolvidos três personagens principais: Edgar (capitão de artilharia do forte), Alice (sua mulher, ex-atriz) e Kurt (comandante da estação de quarentena). Toda a trama está relacionada com a ira, mas sobretudo com os sucessivos insucessos de homem desesperado em busca de afirmação social. A relação entre o capitão e sua mulher ilustra a pulsão de morte, a partir do ímpeto para a destruição do mundo do capitão por ele mesmo. Este patético destino é inseparável, porém, da pulsão de vida; num vai-vem constante e mesmo alucinante.

Isto permite uma breve digressão sobre a questão pulsional em Strindberg.

Garoto, brincávamos no terreiro do colégio em que estudava, jogando bolas de gude coloridas. Eu usava com freqüência bolinhas de aço (chamávamos de "bilhas") retiradas das rodas de carrinhos de rolimã. Sucedia que muitas vezes elas corriam velozes para cantos de vegetação, sebes, plantas; o que dificultava sobremodo encontrá-las. Um dia sugeri que corrêssemos o risco de lançar uma segunda bolinha e, atentamente, observássemos a sua trajetória. Correríamos o risco de perder mais uma, mas talvez pudéssemos achar a segunda... Valeria a pena? Quem sabe? Só tentando. 
Nunca podia imaginar que a cena da infância estaria já em Shakespeare, precisamente no "Mercador de Veneza". Trata-se da cena em que Bassânio pede, pela segunda vez, dinheiro emprestado ao amigo Antonio para escapar da chantagem de Shylock. Assim fala Bassânio: "No tempo em que ia à escola, se perdia uma flecha, atirava outra com o mesmo ímpeto e na mesma direção; depois, seguindo cuidadosamente a sua trajetória, acontecia-me de encontrar a primeira e assim, arriscando duas, recuperava muitas vezes as duas... Se te compraz (dirigindo-se a Antonio) atirar agora uma outra flecha do mesmo modo que a primeira, não duvido que, seguindo sua trajetória desta vez com maior atenção, eu recupere todas as duas ou pelo menos traga de volta esta segunda que arriscaste, restandote sempre grato e devedor da primeira" (Shakespeare, 1596/1988: 437).

$\mathrm{O}$ movimento pulsional procede de acordo com este modelo. O sujeito, primeiro, acredita que perdeu o que pensava ter (o objeto)... No segundo tempo, pode encontrar aquilo que pensa que não obteve anteriormente (a satisfação).

A ênfase está colocada no fato de que, renunciando-se à satisfação, perde-se tudo; até aquilo que não se tem. Que imagem espetacular para aludir à lógica pulsional e mais ainda à estrutura da repetição. Esta estaria ainda vinculada à idéia hegeliana de "negação da negação".

Para o movimento sonoro da repetição ouçamos uma fuga de Bach... A flecha ou a bolinha devem ser lançadas pela segunda vez na mesma direção e com o mesmo ímpeto (força). O termo alemão que Freud utiliza para falar da repetição é wiederholung, palavra composta por wieder (outra vez, de novo, ainda) - tão presente no discurso da primeira infância - e pelo verbo holen (ir pegar de novo, alcançar de novo).

O fragmento de um poema de Heráclito ("ao arco é dado o nome de vida e a sua obra é morte") é utilizado por J. Lacan no seu seminário "Os quatro conceitos fundamentais da psicanálise" (1964), item "a pulsão parcial e seu circuito": "o que a pulsão integra de saída em toda a sua existência é uma dialética do arco e da flecha. O fundamental é o vai-vem em que ela se estrutura" (citado em Ricci, 2005: 17).

Uma (impossível) renúncia pulsional abre caminho para a (hipótese) da satisfação e seu destino, conforme recorda Giancarlo Ricci (2005).

Por paradoxal que possa parecer, também a pintura de Strindberg nos ajuda a compreender o seu interesse nos dramas intimistas quase sempre referidos ao casal e à família, que tanta influência causaram no cineasta, também sueco, Ingmar Bergman. No filme "Cenas de um casamento", dirigido por Bergman, a "cena" doméstica já está viva em Strindberg. No filme "Fanny e Alexander", Bergman o termina com uma cena onde duas personagens femininas falam de seu desejo de 
montar "O sonho" (1901), de Strindberg. E na novela "Depois do ensaio", ainda de Bergman, feita para a televisão sueca, a ação se passa após um ensaio de "O sonho" na forma de um diálogo entre o diretor e uma de suas atrizes. "O sonho" não é apenas uma paixão deste grande ícone do cinema; é também uma metáfora de Strindberg para o inconsciente e para a própria psicanálise, que se funda n' $A$ interpretação dos sonhos, de Sigmund Freud.

Muitos consideram que Strindberg tenha sido um cineasta antes do cinema. Isto porque nele a idéia de "corte" já está presente, determinando o ritmo, a leitura e a vivência dos fatos cênicos. Mas de fato a idéia de "corte" atravessa toda a pintura do dramaturgo. Vejamos como.

Sua primeira pintura intitula-se "Ruínas do castelo de Tulborn na Escócia" e data de 1872. O autor viajou muito, viveu entre França, Suíça, Alemanha e Dinamarca, experimentou o exílio e freqüentou os círculos artísticos de Grez-sur-Loing, nas cercanias de Paris. Ali, em 1895, chegou a travar contacto com Paul Gauguin ${ }^{8}$. Foi amigo dos líderes oposicionistas da arte oficial sueca como Carl Larsson e Karl Nordströn. Larsson chegou a pintar um desenho para calendário (1883) onde retrata um brinde na pensão para artistas suecos em que Strindberg aparece em primeiro plano, à direita. Em 1896, desfrutou de uma boa temporada na companhia de Edward Münch, que chegou a retratá-lo?.

Sua pintura, que possuía um caráter de vanguarda inequívoco, custou a ser reconhecida; mas, atualmente, é considerada como inovadora (Grannath, 2005), criativa, precursora do que mais tarde será denominado de expressionismo abstrato americano dos anos 50 e também do informalismo.

Seu legado estético está centrado na paisagem, onde estão ausentes tanto a figura humana, quanto qualquer outra referência a um espaço previamente conhecido. Entretanto, sua técnica nos oferece cortes planos em espaços referidos à perspectiva e à profundidade que resultam em sensação angustiosa, tão cara a Münch e ao seu tempo, e mesmo claustrofóbica em pleno terreno ou zona paisagística totalmente livre e aberta. Por aí se capturam aspectos centrais de sua angústia interior, cravada na contradição e ambivalência de sentimentos. Sempre pintando "paisagens", por certo irreconhecíveis na realidade, Strindberg costumava passear pelas manhãs e tardes no arquipélago de Kimemendö, na Suécia, retornando sempre à casa para pintar em estúdio. As cores que utiliza são quentes, telúricas; suas pinceladas são fortes. Como na melhor tradição inglesa, a natureza vai ser reflexo de seu tormento interior ${ }^{10}$ e nem mesmo o senso de humor, dito britânico, estará ausente. Em algumas circunstâncias observará os seus próprios quadros a partir de um foco luminoso que, projetando sombras ou realçando aspectos da pintura, permitirá efeitos de ilusão / alusão surpreendentes. 
Esse tormento está, talvez, associado a um pesado legado afetivo e ideológico de natureza religiosa e cristã, particularmente de caráter tomista, mas re-interpretado na Suécia protestante. Um certo individualismo intimista, de acento calvinista, interage com o integrismo cristão romano espalhando-se por um espectro muito grande. Uma interessante hipótese é a de que o neotomismo chega à Suécia através do exílio dos jesuítas na Rússia que os acolheu desde que a Companhia foi extinta em fins do século XVIII. O fato é que há um conjunto de valores religiosos conservadores que pulsa na obra de Strindberg malgrado o combate que o autor move contra esses mesmos valores. As posiçôes que assume na prática com relação à instituição do casamento em geral, as questôes pessoais suscitadas pelo seu próprio casamento, o primeiro (1877-1891), com Siri ${ }^{11}$, para não falar dos outros dois $^{12}$, as posiçôes progressistas que assume no tocante à defesa do divórcio e das lutas pelos direitos das mulheres (mas sempre com reservas), a coletânea de contos intitulada "Casamentos" publicada em dois volumes $(1883 ; 1885)$, que the valeu um processo por blasfêmia; todo esse impressionante conjunto de açôes concretas se choca violentamente com uma aspiração de perfeição, completude e controle absoluto inscrita no pensamento de Santo Tomás de Aquino (Neder, 2000). O sentimento de culpa é nevrálgico neste sistema de pensamento, tão forte no Ocidente e tão presente na infância de August Strindberg. A esse respeito, seu epitáfio resume de maneira dolorosa a sua vida e nos confronta diretamente com o tomismo: tudo foi expiado, o único monumento que eu peço é uma cruz negra e minha história. Expiação e cruz negra, símbolos marcantes que se transformam em gala, morte e luto na vida e obra de Strindberg. Em "Há crimes e crimes" (1899), o autor antecipa a função e o papel do superego freudiano ao sugerir que há crimes não capitulados no código penal que, todavia, clamam a consciência e instauram o aguilhão da culpa, em certos casos sem remissão ou perdão conforme a norma protestante.

De certo modo, podemos falar que August Strindberg viveu intensamente a representação do "casamento como sacramento", mas como verdadeiro patíbulo...

\section{REFERÊNCIAS BIBLIOGRÁFICAS}

Assis, Machado de (1880). Memórias póstumas de Brás Cubas. Rio de Janeiro: Aguilar, 1979.

Begdahl, B. (2002). Documentário sueco intitulado "Ingmar Bergman: intermezzo".

Berlinck, M. T. (2000). Psicopatologia fundamental. São Paulo: Escuta.

Canetti, E. (1998). O outro processo (as cartas de Kafka a Félice). Rio de Janeiro: Espaço e Tempo. 
Cerqueira Filho, Gisálio (2001). In nomine Pater: a Ciência Política e o Teatro Intimista de Auguste Strindberg. Antropolítica. Revista Contemporânea de Antropologia e Ciência Política, 10/11, 173-180.

Grannath, Ol. (2005). Auguste Strindberg: painter, photographer writer. Londres: Tate Modern Gallery.

Heliodora, B. (2005). Psicanálise demais, teatro de menos. O Globo, Segundo Caderno, 26 de março.

Márquez, G. (2002). Vivir para contarla. Barcelona: Editorial Sudamericana.

Neder, G. (2000). Iluminismo jurídico-penal luso-brasileiro: obediência e submissão. Rio de Janeiro: ICC / Freitas Bastos.

Pereira, M. E. C. (2003). Macbeth e o assassinato do sono: um ensaio psicanalítico sobre a insônia. Trabalho apresentado no VIIo Encontro Científico da Associação Universitária de Pesquisa em Psicopatologia Fundamental, Petrópolis, RJ.

Ribeiro, E. (1994). Lady MacBeth continua lavando as mãos: retrato de Berlim e da Alemanha no diário de Witold Gombrowicz. Revista Humanidades, 10, 3, 258-270.

Ricci, G. (2005). As cidades de Freud. Rio de Janeiro: Jorge Zahar.

Shakespeare, W. (1603). Hamlet. Rio de Janeiro: Aguilar, 1988.

- (1596). O mercador de Veneza. Rio de Janeiro: Aguilar, 1988.

Zischler, H. (2005). Kafka vai ao cinema. Rio de Janeiro: Jorge Zahar.

\section{NoTAS}

1 Ficha técnica ao final do artigo.

2 O autor deste ensaio trabalhou como consultor teatral com o grupo "Tá na rua”, dirigido por Amir Haddad, na peça "Morrer pela Pátria".

3 Traduzida para o português por Gisálio Cerqueira e Luiz Fabiano de Freitas.

4 Inaugurado em 1910 na Rua Norra Bantoget, no 20, em Estocolmo. O Teatro Intimista e a dramaturgia de August Strindberg muito influenciaram o cineasta sueco Ingmar Bergman.

5 Canetti, Elias (1998). O outro processo (as cartas de Kafka a Félice), Rio de Janeiro: Editora Espaço e Tempo. Ver ainda Hanns Zischler (2005). Kafka vai ao cinema, Rio de Janeiro: Jorge Zahar Editor.

6 Célebre obra de Franz Kafka.

7 Bergman, Ingmar (2002). Última peça teatral dirigida pelo cineasta sueco: trata-se de "Ghost" (“Espectro”, Ibsen, 1881).

8 Paul Gauguin chegou a solicitar a Strindberg que escrevesse o texto do catálogo para uma de suas exposições de pinturas. Sua carta de recusa foi tão eloqüente que Gauguin solicitou permissão para incluí-la no referido catálogo... 
9 Pintura: “August Strindberg" (1892), Modern Museet, Stockholm, (122 cm X $91 \mathrm{~cm})$, por Edward Münch (1863-1944).

10 Strindberg pintou muitas tormentas, muitos mares revoltosos, ondas gigantescas e, às vezes, com referência aos sentimentos, como o quadro "Noite do Ciumento", 1893, (Night of Jealousy - $41 \mathrm{~cm}$ X $32 \mathrm{~cm}$ ), Strindberg Museum, Stockholm.

11 O primeiro casamento foi com a baronesa sueca Siri von Essen, mais tarde atriz do Teatro Dramático Real, que encena "Senhorita Júlia" no papel principal em 1899. Com ela tem três filhos: Karin, Greta e Hans.

12 O segundo casamento (1893) foi com a jornalista austríaca Frida Uhl, com quem vive até 1899 e tem uma filha: Kerstin. O terceiro casamento se dá com a atriz norueguesa Harriet Bosse. Nos últimos quatro anos de vida apaixona-se pela jovem atriz do "teatro íntimo" Fanny Falkner, com que não chega a casar-se.

\section{Anexo}

\section{FICHA TÉCNICA DA PEÇA TEATRAL "X, Y E S"}

"X, Y e S", dramaturgia e direção geral de Antonio Quinet.

Atores: Alcemar Viera, Flávia Ribeiro, Paula Alexander e Talita Leoneli.

Assistente de direção: Boris Trindade Jr.

Música: Sigga Malaguti

Direção musical: José Eduardo Costa Silva

Preparação de voz: Ana Calvente

Direção de movimento: Tatiana Rodrigues Faria

Ambientação cenográfica: Anna Bella Geiger

Assessoria de ambientação cenográfica: Bruno de Carvalho

Iluminação: Aurélio de Simoni

Consultoria de figurino: Marcelo Olinto

Visagista: Carlinhos Mellow

Consultoria: Bia Junqueira

Produção: Paulo Mattos

Assistente de Produção: Diana Aranha

Design: Mameluco - Noni Geiger

Assessoria de imprensa: Elisabeth Camarão

Fotografia: Lucas Van de Beuque

Recebido em 30 de setembro de 2005

Aceito para publicação em 27 de outubro de 2005 